\title{
Neonatal brain abscess development following fetal scalp electrode placement: a rare complication
}

\author{
T. Fick $^{1}$ (D) P. A. Woerdeman ${ }^{1}$
}

Received: 14 January 2021 / Accepted: 24 March 2021 / Published online: 6 April 2021

(C) The Author(s) 2021

\begin{abstract}
A fetal scalp electrode (FSE) is a frequently used investigation during labor. However, it is an invasive procedure which can lead to complications. Our patient developed a very large brain abscess after initial superficial infection of the skin site due to an FSE. The patient was admitted to the hospital after an asymmetric growth of the skull was noticed with no further signs of clinical illness. MRI showed a very large brain abscess which was aspirated and treated with antibiotics for 10 weeks. A 2-year follow-up showed only a slight developmental delay in gross motor skills. Only once before a similar case has been described at which the patient developed a brain abscess after superficial infection of the scalp following an FSE. In both cases, the brain abscess was noticed due to an asymmetric growth of the skull without any further signs of clinical illness. A brain abscess has a high mortality and morbidity rate, and early diagnosis is vital for the optimal outcome. We therefore recommend to organize an out-patient clinical follow-up for every infant with a superficial infection of the skin site after placement of an FSE.
\end{abstract}

Keywords Neonatal $\cdot$ Brain abscess $\cdot$ Fetal scalp electrode

\section{Abbreviations \\ CTG Cardiotocography \\ FSE Fetal scalp electrode \\ SDS Standard deviation score}

\section{Introduction}

Cardiotocography (CTG) is a technique to monitor the fetal heart rate and uterine contractions during labor. The indication is broad and can variate between countries [1]. CTG can be done externally by using two transducers on the mothers' abdomen and internally by using an electronic transducer connected to the fetal scalp by an electrode. A fetal scalp electrode (FSE) accounts for a more accurate measurement and is less affected by movement compared to external monitoring and is

T. Fick

t.fick-3@umcutrecht.nl

1 Department of Neurosurgery, University Medical Center Utrecht, Wilhelmina Children's Hospital, Lundlaan 6, 3584

EA Utrecht, Netherlands therefore frequently used. In $22 \%$ of labors in clinical centers in the USA, an FSE is used [2]. However, this is an invasive procedure and can lead to complications. It is associated with a 1.3\% rate of scalp ulcers and has an increased risk of developing a cephalohematoma and neonatal sepsis [3]. Scalp abscess development following FSE is well described and is present in up to $4.5 \%$ of the cases [4-6]. Although rare, more serious complications, such as cranial osteomyelitis and epidural abscesses, have been described [7, 8]. We present a case of an 8-week old infant with a very large brain abscess due to placement of an FSE.

\section{Case}

Our patient was given birth after 38+6/7 weeks of gestation (Apgar score 9/10). A fetal scalp electrode for cardiotocography was indicated for monitoring due to oligohydramnios. Birth length and weight measured $49 \mathrm{~cm}$ (SDS -1.44 ) and $2.88 \mathrm{~kg}$ (SDS -1.1), respectively. Head circumference was $34 \mathrm{~cm}$ (SDS -1.25). The FSE left a small laceration which after a couple of days showed infection (Fig. 1). This was treated with fusidic acid cream $20 \mathrm{mg} / \mathrm{g}$ for 5 days and led to a full recovery of the skin site. 


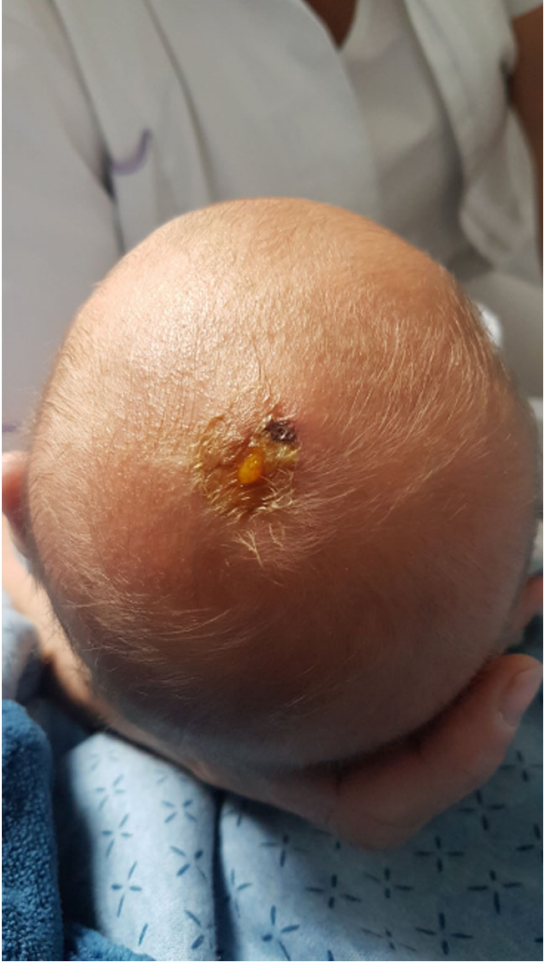

Fig. 1 Five days postpartum superficial infection of the laceration left parasagittal where the fetal scalp electrode was placed during delivery

At the infant consultation clinic at 8 weeks of age, an asymmetry of the skull was noticed. Body length and weight followed normal growth patterns, but head circumference revealed progressive head growth with crossing of percentiles (SDS +1.33). Although the child had no neurological deficits or signs of clinical illness, the fontanel was tensed and sutures were splayed prompting referral to our hospital for consultation and MRI imaging. The MRI showed a large mass lesion in the right hemisphere suspect for abscess based on the ringenhanced aspect on the T1-weighted sequence with contrast and hyperintense with hypointense walls on T2 (Fig. 2). Blood work showed leukocytes of $26.4 \times 10^{\wedge} 9 / 1$.

Surgery was indicated, and $80 \mathrm{ml}$ of green purulent fluid was aspirated in the OR using a blunt Dandy needle (Fig. 3a and $b$ ). We stopped surgery when aspiration was no longer possible due to resistance. Post aspiration ultrasound imaging in the OR revealed a small abscess residual.

Culture showed multiple pathogens, i.e., Gardnerella vaginalis, Prevotella amnii, and Dialister micraerophilus for which we initiated intravenous antibiotic treatment with ceftriaxone $(100 \mathrm{mg} / \mathrm{kg} / \mathrm{day}$ in 1 dose) and metronidazole ( $30 \mathrm{mg} / \mathrm{kg} /$ day in 3 doses). Postoperatively the patient remained clinically stable. Head circumference was measured daily, and ultrasound was planned 1 week after surgery. Ultrasound imaging showed significant increase of the remnant abscess. MRI imaging of the head confirmed the
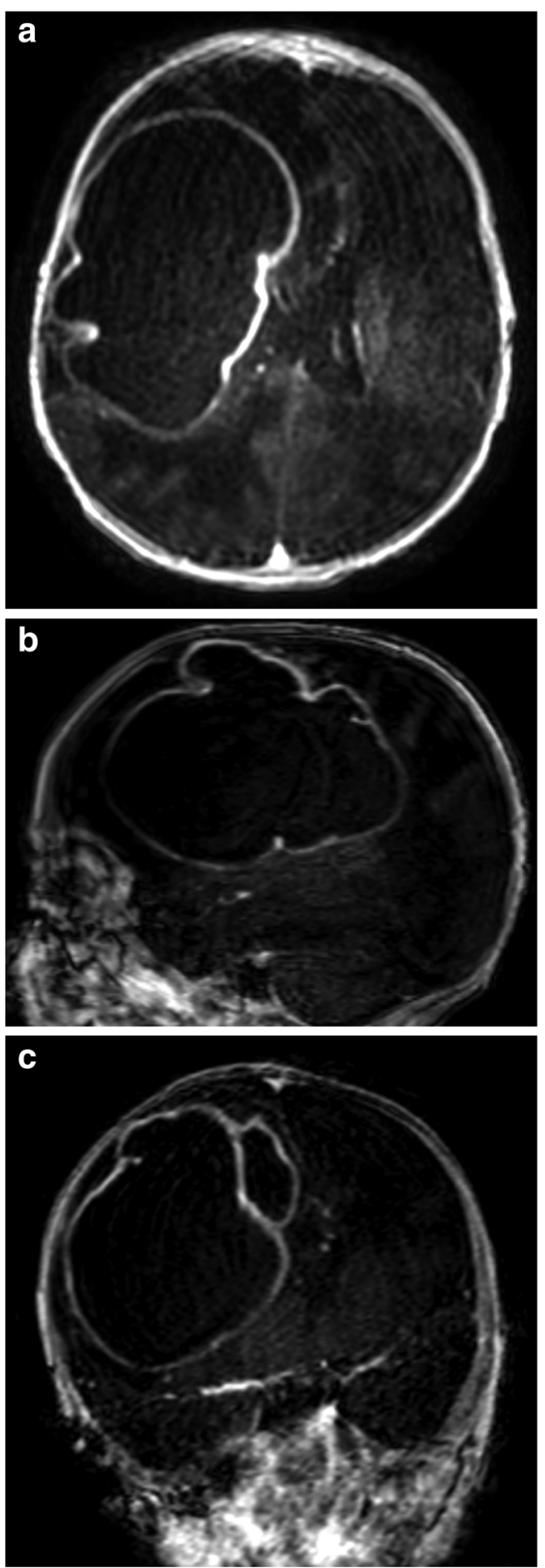

Fig. 2 T1-weighted MRI with contrast showing a ring enhanced lesion in the right hemisphere with surrounding edema and midline shift. Mass dimensions: $78 \times 51 \times 58 \mathrm{~mm}$ with an estimated volume of $120 \mathrm{ml}$. a Axial view. b Sagittal view. c Coronal view

recurrence of the abscess with almost similar previous dimensions. Surgery was repeated, and this time $120 \mathrm{ml}$ of purulent fluid could be aspirated. Culture revealed Mycoplasma hominis for which ciprofloxacin $(30 \mathrm{mg} / \mathrm{kg} /$ day in 2 doses) was added to the antibiotic treatment. Weekly ultrasound 
Fig. 3 a Aspiration through right frontal incision. b Syringe showing purulent aspirate
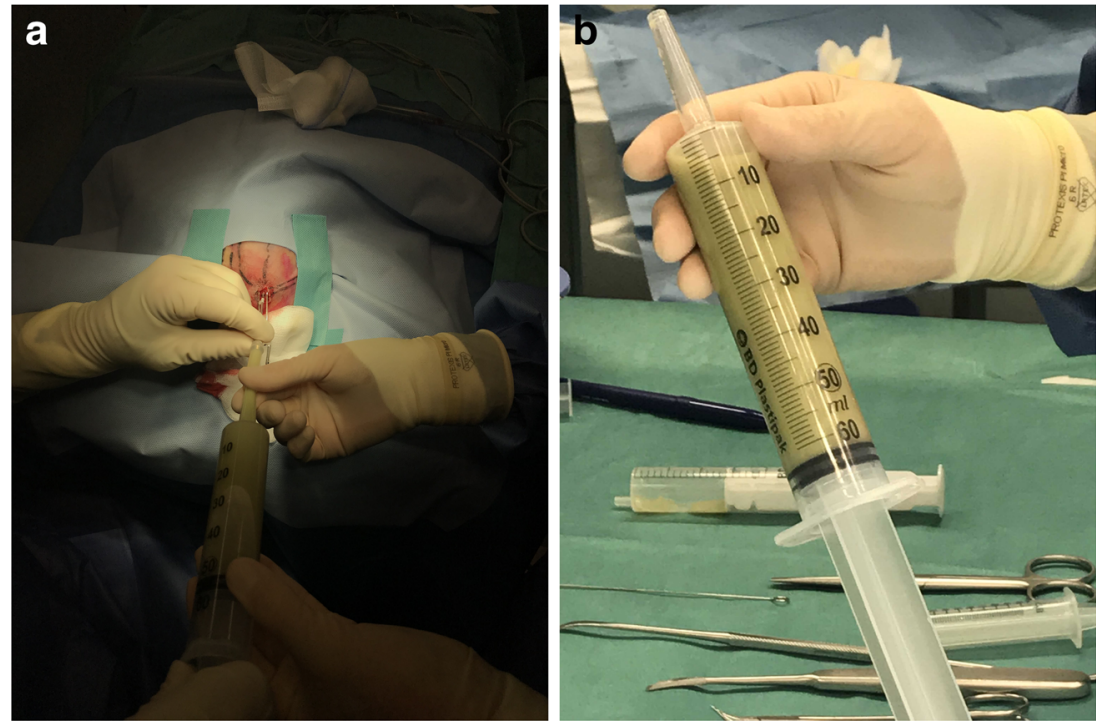

follow-up showed a stable volume of the remaining mass, and after 5 weeks, repeat MRI showed significant decrease (>90\%) of the abscess volume.

After 6 weeks, the patient was discharged from the hospital in good clinical condition. Intravenous antibiotic treatment was continued for 8 weeks total after which ceftriaxone and metronidazole were stopped and ciprofloxacin was continued for another 2 weeks orally. At 2-year follow-up, our patient showed a slight developmental delay in gross motor skills. Further development was average for his age.

\section{Discussion}

We presented a case-report of an infant developing a very large brain abscess following a superficial infection of the scalp due to an FSE placement. FSE is a widely used instrument during labor in clinical centers. Knowledge about the possible complications is therefore important. Brain abscess is a serious disease with a mortality rate in children of 3.7$12.5 \%$ [9-12]. Furthermore, morbidity rate is high with, after surgery, $29 \%$ of the patients suffering from epilepsy within the first month and up to $41.7-59 \%$ in the long term [2, 10, 13]. Moreover, brain abscess at young age is associated with mental retardation $[10,14]$.

To the best of our knowledge a cerebral abscess due to an FSE has been described only once before in literature [15]. The previously described case showed several similarities to our case. A deep laceration was noted after removal of the FSE. Microflora associated with the cervicovaginal region was cultured, and treatment consisted of wound cleansing and antibiotics for 7 days. After 6 weeks, an enlarged head circumference was noticed, and MRI imaging was performed. The abscess was treated with a one-time aspiration.
In both patients, the brain abscess was diagnosed after measuring an enlarged head circumference at the local child health clinic while both in clinically good condition without neurological deficits or fever. Since the development of the abscess can be clinically silent, follow-up is vital to intercept this illness in an early stage. Furthermore, late diagnosis and treatment is related to a higher mortality and morbidity rate [9, 16]. It is therefore recommended to organize an out-patient clinical follow-up for every infant with a superficial infection after placement of an FSE, which should comprise neurological examination and measurement of the head circumference. When abnormal findings are present, neuroimaging examination is strongly advised.

\section{Conclusion}

A brain abscess in neonates is a possible life-threatening illness with a significant risk of developing epilepsy and mental retardation. These brain abscesses can develop progressively into very large volumes without signs of clinical illness. Therefore, screening and follow up of neonates after superficial infection due to an FSE is highly recommended.

Availability of data and material Not applicable.

Code availability Not applicable.

\section{Declarations}

Consent for publication Informed consent was obtained from the parents of the participant to publish the data described in this study

Conflict of interest Not applicable. 
Open Access This article is licensed under a Creative Commons Attribution 4.0 International License, which permits use, sharing, adaptation, distribution and reproduction in any medium or format, as long as you give appropriate credit to the original author(s) and the source, provide a link to the Creative Commons licence, and indicate if changes were made. The images or other third party material in this article are included in the article's Creative Commons licence, unless indicated otherwise in a credit line to the material. If material is not included in the article's Creative Commons licence and your intended use is not permitted by statutory regulation or exceeds the permitted use, you will need to obtain permission directly from the copyright holder. To view a copy of this licence, visit http://creativecommons.org/licenses/by/4.0/.

\section{References}

1. Schulten PS, Suppelna JP, Dagres T, Noé G, Anapolski M, Reinhard J, Krentel H, Tempfer C, Schiermeier S (2018) International guidelines for the application of cardiotocography. Z Geburtshilfe Neonatol 222(2):66-71

2. Canpolat M, Ceylan O, Per H, Koc G, Tumturk A, Kumandas S, Patiroglu T, Doganay S, Gumus H, Unal E, Kose M, Burcu Gorkem S, Kurtsoy A, Kursat Ozturk M (2015) Brain abscesses in children: results of 24 children from a reference center in central Anatolia, turkey. J Child Neurol 30(4):458-467

3. Kawakita T, Reddy UM, Landy HJ, Iqbal SN, Huang CC, Grantz KL (2016) Neonatal complications associated with use of fetal scalp electrode: a retrospective study. BJOG An Int J Obstet Gynaecol 123(11):1797-1803

4. Glaser JB, Engelberg M, Hammerschlag M (1983) Scalp abscess associated with mycoplasma hominis infection complicating intrapartum monitoring. Pediatr Infect Dis 2(6):468-470

5. Okada DM, Chow AW, Bruce VT (1977) Neonatal scalp abscess and fetal monitoring: factors associated with infection. Am J Obstet Gynecol 129(2):185-189
6. Onyeama CO, Srinivasan H, Lotke M, Vickers DL (2009) Subgaleal abscess and E. coli septicemia following scalp electrode in a preterm newborn: a case report. J Matern Neonatal Med 22(12):1201-1203

7. Listinsky JL, Wood BP, Ekholm SE (1986) Parietal osteomyelitis and epidural abscess: a delayed complication of fetal monitoring. Pediatr Radiol 16(2):150-151

8. McGregor JA, McFarren T (1989) Neonatal cranial osteomyelitis: a complication of fetal monitoring. Obstet Gynecol 73(3):490-492

9. Auvichayapat N, Auvichayapat P, Aungwarawong S (2007) Brain abscess in infants and children: a retrospective study of 107 patients in Northeast Thailand. J Med Assoc Thail 90(8):1601-1607

10. Renier D, Flandin C, Hirsch E, Hirsch JF (1988) Brain abscesses in neonates. A study of 30 cases. J Neurosurg 69(6):877-882

11. Sahbudak Bal Z, Eraslan C, Bolat E, Avcu G, Kultursay N, Ozkinay F, Kurugol Z, Vardar F (2018) Brain abscess in children: a rare but serious infection. Clin Pediatr (Phila) 57(5):574-579

12. Shachor-Meyouhas Y, Bar-Joseph G, Guilburd JN, Lorber A, Hadash A, Kassis I (2010) Brain abscess in children - epidemiology, predisposing factors and management in the modern medicine era. Acta Paediatr Int J Paediatr 99(8):1163-1167

13. Moss DS, McLone DG, Arditi M, Yogev R (1988) Pediatric cerebral abscess. Pediatr Neurosci 14(6):291-296

14. Suiton DL, Ouvrier RA (1983) Cerebral abscess in the under 6 month age group. Arch Dis Child 58(11):901-905

15. Koot RW, Reedijk B, Tan WF, De Sonnaville-De Roy Van Zuidewijn MLCS (1999) Neonatal brain abscess: complication of fetal monitoring. Obstet Gynecol 93(5 SUPPL):857

16. Sheenan JP, Jane JA, Ray DK, Goodkin HP (2008) Brain abscess in children. Neurosurg Focus 24(6):1-5

Publisher's note Springer Nature remains neutral with regard to jurisdictional claims in published maps and institutional affiliations. 